\title{
REPENSANDO E RESSIGNIFICANDO A GESTÃO DEMOCRÁTICA DA EDUCAÇÃO NA “CULTURA GLOBALIZADA"
}

\author{
Naura Syria Carapeto Ferreira*
}

\begin{abstract}
RESUMO: Tanto em extensividade como em intensividade, as transformaçōes científico-tecnológicas, econômico-sociais, ético-políticas e culturais na contemporaneidade, mais profundas do que a maior parte das mudanças características de todos os períodos históricos até então vividos, têm impactado mentes e coraçōes de toda a humanidade, exigindo pensar e ressignificar a formação de profissionais da educação e a gestão da educação. Este texto aponta para a necessidade de humanizar a formação e as condiçōes de existência dos profissionais da educação e da gestão da educação ressignificando-as com outra base ética, que permita fazer frente aos desafios violentos da "cultura globalizada" na "sociedade transbordante", "insatisfeita" e "excludente", constituída de "ressentimentos" e de exacerbação do individualismo rumo à formação da cidadania plena.
\end{abstract}

Palavras-chave: Gestão democrática da educação. "Cultura globalizada". Formação. Cidadania. Humanização das relações.

\section{RETHINKING AND RESIGNIFYING THE DEMOCRATIC MANAGEMENT OF EDUCATION IN THE “GLOBALIZED CULTURE”}

ABSTRACT: Both in their extensiveness and intensiveness, the scientific-technological, economic-social, political-ethical and cultural changes in contemporary life have been much deeper than most changes that happened throughout history. They impacted on the minds and hearts of the whole humanity, requiring that we contemplate and resignify the education of education professionals and the management of education. This text points out a need for humanizing the education and living conditions of professionals in education and education management. They should be redefined based on a

Professora titular da Faculdade de Ciências Humanas, Letras e Artes da Universidade Tuiuti (PR) e professora (aposentada) da Universidade Federal do Paraná (UfPR). E-mail: nauraf@uol.com.br/naura@utp.br 
Repensando e ressignificando a gestão democrática da educação...

new ethics that allows to face the violent challenges of the "globalized culture" in the "overflowing society", that is "dissatisfied" and "exclusory", built on "resentments" and the exacerbation of individualism, and to move toward the formation of a whole citizenship.

Key words: Democratic management of education. "Globalized culture". Professional education. Citizenship. Humanization of relationships.

\section{Introdução}

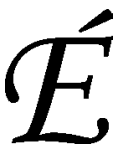

inconteste que a história humana é marcada por certas "descontinuidades", não se desenvolvendo de maneira uniforme. Essas "descontinuidades" têm sido relatadas por meio das análises críticas dos intelectuais de cada tempo, os quais tentam interpretar a realidade para nela intervir e/ou transformá-la. Todavia, as transformaçôes hodiernas e os modos de vida que a contemporaneidade fez surgir nos afastam de todos os tipos tradicionais de ordem social, de uma forma sem precedentes em toda a história da humanidade. Tanto em extensividade como em intensividade, as transformaçōes científico-tecnológicas, econômico-sociais, ético-políticas e culturais no mundo globalizado são mais profundas que a maior parte das mudanças características de todos os períodos históricos até então vividos, "decidindo", influenciando e afetando "pedagogigamente" todos os seres humanos. No plano da extensividade, serviram para estabelecer formas de interligação social à escala do globo; em termos de intensividade, vieram alterar algumas das características mais íntimas e pessoais da nossa existência cotidiana. Extensividade e intensividade, no entanto, não se excluem. Ambas, coetaneamente, impactam e desafiam todos os povos e seres humanos que os compõem, porque se completam no sentido de que uma gera e nutre a outra.

A globalização econômica significa unificação econômica, mas também significa uma crescente fragmentação econômica, social e política que se reflete, tanto uma quanto a outra, em toda a população terrestre, afetando as mentes e os coraçóes dos seres humanos, desde os que têm acesso aos bens culturais como os que deles são privados tornando-se cada vez mais excluídos. Por um lado, uma tendência à desrealização toma todas as pessoas que se apegam demasiadamente à "perfeição limpa" das matemáticas ou ao rigor lúdico da informática e, por outro, a desrealização configura-se de forma cada vez mais amplia- 
da na miserabilidade humana, que se faz cada vez maior no mundo. A tecnologia da simulação virtual não pode senão reforçar esse risco de desrealização, ao dar caráter pseudoconcreto e pseudopalpável às entidades imaginárias que ocupam hoje o universo humano. E o que resultou disso?

Resultou um mundo "sedutor", "fascinante" e, contraditoriamente, atemorizador, excludente, cruel. Resultou, de forma extensiva e intensiva, na agudização da riqueza e da pobreza humanas e em todas as suas nefastas conseqüências: o vazio, a insegurança, o medo, a angústia, o terror, a desrealização, a perda do sentido da vida, a exclusão. Para muitos trata-se de uma crise do processo civilizatório, uma inversão das condições que, na perspectiva de Norbert Elias (1973, 1994), teriam definido o curso do processo civilizatório. ${ }^{1}$ A crença na formação de uma "sociedade mundial" pacífica e humana é abalada pela proliferação das guerras entre nações, pelo acirramento da divisão entre um "mundo" hegemônico constituído de uma minoria de poderosos e o "resto" do mundo tratado como resto, como descartável, como sobra humana coisificada.

Como um fetiche, a globalização é "falada", "usada" com freqüência sem ser entendida concretamente, significando muitas vezes o oposto, mas tendo algo em comum: constitui-se como um poder oculto que agita o mundo, que determina as vidas humanas, dominando-as cada vez mais. Todos os problemas sociais, todas as crises e catástrofes, na atualidade, são relacionados com a "globalização", assim como se fala de um mundo mais seguro e até de um possível "governo democrático mundial".

$\mathrm{Na}$ mesma escala em que ocorre a globalização do capitalismo, considerada um processo civilizatório (Ianni, 1999), verifica-se a globalização do mundo do trabalho. No âmbito da fábrica global, criada com a nova divisão internacional do trabalho, e da produção e dinamização do mercado mundial, amplamente favorecidas pelas tecnologias eletrônicas, colocam-se novas formas e novos significados para o trabalho, gerando o nãotrabalho, fato este que vai exigir novas compreensões e responsabilidades sobre o uso e o rumo decisivo de todos os avanços da ciência e da tecnologia na formação de profissionais em geral, de profissionais da educação e na formação para o exercício da cidadania. Portanto, novas prioridades impõem-se para novas políticas e, em especial, para a gestão democrática da educação comprometida com a qualidade da formação humana. 
Repensando e ressignificando a gestão democrática da educação...

A economia globalizada não é a economia mundial que, aliás, é um fenômeno existente, pelo menos, desde o século XVI, mas uma economia cujas atividades estratégicas, fundamentais, como a "inovação", o capital e a gestão da empresa, funcionam em escala planetária em tempo real "e ao vivo"2 (Carnoy \& Castells, 1993; Castells, 1996; Tolda, 2001; Sousa Santos, 2001) por meio dos recursos tecnológicos proporcionados por telecomunicações, sistemas informáticos, microeletrônica e redes informatizadas. Tudo se globalizou e continua a se globalizar: capital, tecnologia, gestão, informação, mercados internos, terrorismo, racismo e violência, crueldade, competição, coisificação, banalização, ocasionando, em extensividade e em intensividade, uma revolução no mundo do trabalho e na sua organização, na produção de bens e serviços, nas relações internacionais e nas culturas locais, transformando o próprio princípio das relações humanas e da vida social.

No plano socioeconômico o capital, centrado no monopólio crescente das novas tecnologias microeletrônicas associadas à informática, rompe com as fronteiras nacionais e globaliza-se de forma violenta e excludente, sobretudo o capital financeiro-especulativo que dilapida os fundos públicos nacionais. No plano ético-político tem-se a reafirmação do ideário neoliberal: a "nova era do mercado" apresenta-se como a única via possível da sociabilidade humana que, logicamente, torna-se cada vez mais individualista e utilitarista.

O desemprego estrutural demarca não apenas o aumento do exército de reserva, mas especialmente o excedente de trabalhadores. Sob a vigência de relações de propriedade privada, aumentam a miséria, a fome e a barbárie social. A crise do trabalho assalariado constitui-se num dos problemas políticos e psicossociais mais agudos da história humana, evidenciando uma das contradições mais profundas dos tempos atuais: "A classe trabalhadora que sempre lutou pela redução da jornada de trabalho e liberação do tempo livre empenha-se, hoje, desesperadamente para manter-se empregada mesmo à custa da perda de direitos duramente conquistados" (Frigotto, 1998, p. 140). Os profissionais da educação, professores que também sempre, organizadamente, lutaram por melhores condições de trabalho na escolas e nas universidades, sujeitam-se a trabalhar exaustivamente, sem as condiçōes necessárias à qualidade do ensino e da administração, com salários aviltantes.

São transformações tão rápidas que afetam profundamente todos os seres humanos, o meio ambiente, as instituições sociais, as relações de 
trabalho e as relações sociais, ocasionando tremendo impacto pela aplicação das novas tecnologias que "alteram hábitos, valores e tradiçóes que pareciam imutáveis" (Ferreira, 1999, p. 27). Nesse contexto, a educação e a formação de profissionais, que são constituídas e constituintes das relações sociais, reduzem-se ao economicismo do emprego e da empregabilidade, da eficiência e da eficácia, da competitividade, da produtividade e conseqüente entropia da formação humana e da cidadania.

As políticas públicas, emanadas do Estado, anunciam-se nesse "paradigma" e, mediatizadas por lutas, pressões e conflitos, abrem-se a "possibilidades" para implementar sua "face social". Nesse contexto de tal gravidade, a gestão da educação, como tomada de decisões, utilização racional de recursos para a realização de determinados fins (Paro, 2000; Ferreira, 1999, 2004), necessita ser repensada e ressignificada ante a "cultura globalizada", ${ }^{3}$ a partir dessas determinações e à luz dos compromissos com a fraternidade, a solidariedade, a justiça social e a construção humana do mundo.

Mais do que nunca se faz necessário humanizar a formação e as condições de trabalho e de existência dos profissionais da educação. Mais do que nunca se faz necessário ressignificar a gestão da educação a partir de outra base ética, que permita fazer frente aos desafios constantes da "cultura globalizada" na "sociedade transbordante" (Jeudy, 1995) "insatisfeita" (Heller \& Fehér, 1998) constituída de "ressentimentos" (Arendt, 1994) e de exacerbação do individualismo.

\section{A banalização da realidade virtual e da realidade concreta}

Atender, viver e produzir a existência, por meio do trabalho, no mundo que se impõe com todas as suas transformaçôes e, concomitantemente com toda a violência, por meio da mídia em suas diversificadas, evoluídas e aceleradas formas, constitui-se uma exigência que a educação e sua gestão necessitam assumir construindo e reconstruindo coletivamente uma política educacional viva que priorize o humano em todas as pessoas do mundo e no conjunto da humanidade. Essa exigência se torna cada vez maior ante os ditames da "cultura globalizada" que, na atual etapa de desenvolvimento, apresenta características e demandas muito peculiares, contraditórias, complexas, em intensa quantidade e extensividade. Os dias atuais apresentam uma "ordem" em que as "mídias" podem agora, em lugar de se precipitar sobre os acon- 
Repensando e ressignificando a gestão democrática da educação...

tecimentos, em lugar de criá-los, de empolá-los, imprimir-lhes sua incrível dinâmica e sua capacidade de distribuir alucinantes massas de informação. A contemporaneidade é fruto principalmente de uma ordem econômica capitalista mundial que envolve a formação de um tipo especial de Estado e, de modo geral, de tipos de organização, os quais dependem fundamentalmente da estruturação da informação.

Os "meios de comunicação de massa”, a indústria cultural, as corporações da mídia são poderosos agentes culturais que influenciam decisivamente a educação, a socialização dos indivíduos e das coletividades, influenciando no modo pelo qual uns e outros se inserem na sociedade, na cultura, no mercado, na política etc. Em diferentes gradações, a mídia difunde, reitera ou altera quadros mentais de referência de indivíduos e coletividades em todo o mundo, tanto abrindo como delimitando horizontes, tanto fertilizando inquietaçóes como influenciando suas expressões, podendo ser elemento ativo das diversidades e mudanças em todos os níveis da sociedade.

Instituições como as universidades estão, nesse contexto, desafiadas a acompanhar e adaptar-se às alteraçôes ambientais provocadas pela aplicação de novas tecnologias, geralmente implementadas pela iniciativa privada, e desafiadas a produzir tecnologias e formação tecnológica que assegurem a seus egressos a capacidade de um excelente desempenho profissional para garantir o enfrentamento competitivo do "mercado de trabalho".

Assim, a nova realidade exige qualificações cada vez mais elevadas para qualquer área profissional ou qualquer posto de serviço, tornando as necessidades educacionais das populações cada vez maiores, reduzindo essa formação a capacitações sem a base ética necessária à formação humana de todo cidadão para a verdadeira vida em sociedade. Quem não acompanha as mudanças científicas e tecnológicas prematuramente estará inabilitado para o trabalho e para a vida em sociedade que, contraditoriamente, produziu também o "não-trabalho". A formação humana integral que se alicerça na ética humana foi secundarizada pelos ditames da produtividade e da competitividade que o neoliberalismo impõe. O individualismo, como nunca, desenvolve-se em escala sem precedentes, quer pela ausência da formação humana, quer pela "necessidade" de "correr atrás de trabalho" para sobreviver.

Nesse curso do "mundo do mercado" coloca-se a violência como categoria determinante da vida diuturna. Pela rapidez que as $\operatorname{TIC}^{4}$ pro- 
porcionaram a toda a humanidade, o quadro de referência de todos mudou. Todo vivem, sentem, pensam e agem aceleradamente, violentamente, desrespeitando todas as formas humanas de trabalho e de convivência social. Como já afirmei em outro lugar:

Vive-se a violência causada pela transnacionalidade dos modos de pensar, sentir e agir de todas as culturas, abalando valores locais e culturas, "transmutando" formas tradicionais de produção da existência e de organização social. Vive-se o tempo em que "tudo vale e tudo pode e porque tudo pode nada mais vale". Pode-se tudo! E, nesta amoralidade, a violência toma lugar nas suas mais aviltantes formas, afetando indivíduos, famílias, instituições sociais e nações. (Ferreira, 1998; 2001, p. 367)

Constata-se, entretanto, que a grande ausente é justamente a informação nova e relevante. As TIC avançaram mais rapidamente que a própria informação. Neste sentido, é necessário estar atento para evitar um certo "deslumbramento" que tem levado a um uso indiscriminado da tecnologia em suas potencialidades técnicas, em detrimento de suas virtudes científicas, culturais e pedagógicas.

Mais do que nunca a história, como defende Jeudy (1995), oferece a aparência de estar em vias de se escrever, e a variação das posições éticas dá a impressão de uma riqueza de interpretações. A diversidade de "éticas", concepções, crenças e valores possibilita uma riqueza de interpretações ao mesmo tempo em que impossibilita essas interpretaçōes pelo "bombardeio" que efetivam nas mentes e nos corações de todos os seres humanos. "A conquista da democracia, dos seus valores, o triunfo dos direitos e das liberdades são postos em cena 'ao vivo', 'em direto"' (Jeudy, 1995, p. 113), assim como todos os avanços científicos, tecnológicos, culturais e, também, todas as formas de violência produzidas no mundo, em conseqüência do rumo vertiginoso do desenvolvimento que se operou e se opera em todas as dimensóes. Os acontecimentos surgem na máquina de distribuir informação e ninguém dispõe verdadeiramente de tempo necessário para representar o que acontece. A própria idéia de representar, interpretar, compreender os acontecimentos é questionada quanto a ter algum sentido. A abundância de sentidos e significados, que "transpassam" o espaço mediático, nublou mentes e corações sobre o que verdadeiramente tem sentido e significado. Prioridades são questionadas e, por isso, necessitam ser repensadas e ressignificadas. Quais as reais prioridades, que se fa- 
Repensando e ressignificando a gestão democrática da educação...

zem necessárias, para a formação humana e profissional dos cidadãos que a gestão democrática da educação tem de garantir?

Esses novos "sentidos" se situam no "comando" externo das verdadeiras necessidades humanas, como querendo anular a "força motriz" de cada ser que sonha e que tenta buscar sua realização. Esses novos "sentidos" que povoam a galáxia contemporânea acirraram um neo-individualismo que se apresenta com suas "três grandes apoteoses - consumista, hedonista, narcisista” (Sousa Santos, 1991, p. 87). A rapidez da informação e a quantidade de informações apenas parecem autorizar interpretações previamente feitas, isto é, "significações possíveis", 5 que estão ao dispor e, por isso, são incorporadas tumultuadamente, sem sentido, de forma naturalizada e mecânica no íntimo de mentes e corações, em todo o mundo, que têm acesso a essas informaçōes. É neste processo de banalização ${ }^{6}$ e de insignificância da realidade que se funda o excesso ou a mais-valia de sentido dos discursos e das imagens que circulam o espaço público. "A alucinação substitui a cena e o lugar da representação. As mídias conseguiram operar uma gestão competente dos efeitos de fascinação. $\mathrm{O}$ acontecimento pode ser integralmente produzido e a transmissão das imagens televisivas alimenta-se do poder exercido pelo 'em direto'. A imagem e o real podem coincidir!" (Jeudy, 1995) Seria isso uma banalização da fascinação? Sim, é a banalização não só da fascinação, mas da vida e da morte humanas.

A violência banalizada tornou-se o conteúdo da vida cotidiana de quem tem acesso aos meios de comunicação, infelizmente! Todavia, pergunta-se, e para aqueles que não têm acesso a estes bens culturais, o que restou? Sobraram os rescaldos dessa violência, a alienação, a fome, o desemprego, as "carências" de todas as formas de vida humana digna, que vêm a se constituir na reprodução da violência. Sobraram "as brutalidades cometidas contra etnias indígenas, as matanças de delinqüentes ou menores infratores, a epidemia de assaltos, seqüestros e roubos" (Ferreira, 2002, p. 534), a subnutrição, o analfabetismo, a miséria, o sofrimento, a morte. Para todo o planeta sobraram o terrorismo, a produção da inferioridade,

a guerra, a escravatura, o genocídio, o racismo, a desqualificação do outro em objeto ou recurso natural e uma vasta sucessão de mecanismos de imposição econômica (tributação, colonialismo, neocolonialismo e, por último, globalização neoliberal), de imposição política (império, Estado 
colonial, ditadura e, por último, democracia) e de imposição cultural (epistemicídio, missionação, assimilacionismo e, por último, indústrias culturais e cultura de massas). (Sousa Santos, 2002, p. 24)

O que restou para a grande parcela do mundo globalizado que sequer tem o que comer ou vestir, muito menos receber, ver ou apreciar por meio dos poderosos meios de comunicação, as informações bombásticas, ainda que banalizadas e a produção fantasiosa dos "pacotes cinematográficos" recheados de tiros e mortes? Restou apenas a violência das "faltas de" que causam a violência da indignidade, do ódio, da miséria, que perpassa o espaço societário mundial. Restou a violência da discriminação que conduz à incivilidade, ao desespero e à desesperança, pois é evidente que a iniqüidade da distribuição da riqueza mundial, que se agravou nas duas últimas décadas de forma avassaladora, ${ }^{7}$ agudizou a riqueza e a miséria humanas.

Nesse contexto, o matar e o morrer, a mentira, a trapaça, a traição, a ignomínia, assim como todas as formas de violência humana veiculadas por meio da mídia, de forma naturalizada, são, já, conceitos incorporados, por todas as pessoas que têm acesso a esse meios. Mas, principalmente e infelizmente, são assimilados e incorporados pelas crianças e pelos adolescentes, inertes, diante da televisão desde a mais tenra idade, sem mesmo ainda ter conseguido pronunciar corretamente estes termos. Esta incorporação dos conceitos banalizados se dá, por meio da linguagem mediática, "formando" socialmente as mentes e os coraçôes de todos e, em especial, das crianças, permeando a educação infantil de conteúdos não selecionados como prioritários ao seu desenvolvimento, mas como conteúdos priorizados pelo capital que, na "ânsia" de vender e vender cada vez mais, "cultiva" o consumismo de mercadorias, todas banalizadas, completamente sem sentido, conferindo-lhes um outro sentido: o desejo de possuir e de consumir "a qualquer preço".

E, nesse "quadro", o que restou? O vazio! A insegurança! O medo! A angústia! O terror! A perda do sentido da vida! A solidão! Restou a produção, em massa, de mercadorias que coisificam as pessoas e personalizam as coisas, travestindo com outros "significados" a produção destinada ao consumismo, que também precisa, nesta ótica, ser cultivado. Restou o desenvolvimento de inúmeras patologias que são produzidas pela neurose que as determinaçóes do capitalismo globalizado geraram, acentuando antagonismos insuperáveis como riqueza e misé- 
Repensando e ressignificando a gestão democrática da educação...

ria e produzindo a doença que ganhou o "trono" das patologias no mundo: a depressão. ${ }^{8}$ Restou o prazer virtual - para os que a ele têm acesso -, que substitui o real pelo virtual, as relações humanas reais pelas relações virtuais abstratas e fantasiosas. Restou o prazer virtual que é capaz de substituir o prazer real pelo prazer da imaginação, conduzindo homens e mulheres, já desde a infância e a adolescência, a se relacionarem com o computador como se se relacionassem com um ser humano, simplesmente porque por trás de outra máquina existe outro ser humano que também se relaciona da mesma forma. A máquina "facilita" e contraditoriamente "substitui" o verdadeiro diálogo humano de pessoas, o real encontro de mentes e corações. A ilusão da transformação espaciotemporal é tão poderosa que o próprio virtual se apresenta como real, constituindo-se numa perversidade cada vez mais atual.

Esta banalização da vida e da morte, do "amor" e do ódio, do magnífico e do abominável, da riqueza e da pobreza, nas suas mais diversas e diferenciadas formas de expressão, cruas ou travestidas e sob "efeitos especiais" de som, luzes e cores, confirma o pensamento de Adorno segundo o qual a consolidação do processo de "semiformação", em que o conceito foi apreendido de forma medíocre, não significa o cumprimento de um primeiro estágio que deverá ser ultrapassado. $\mathrm{Na}$ verdade, a absorção do banalizado é inimiga mortal da formação (Adorno, 1986), pois distorce a apreensão da realidade delocando-a do realconcreto e distituindo-a de seu verdadeiro sentido e significado, gerando sentimentos induzidos no seio das apreensões. Aprender de forma medíocre é mediocrizar quem aprende, pela absolutização do conteúdo da informação. É desumanizar o ser humano na aquisição da sua "segunda natureza" mediocrizada. É uma "semiformação" que gera um outro tipo de "formação" que bem poderia ser chamada de deformação, pois produz a esquizofrenia pessoal e social. Tal processo gera, realmente, uma dissociação e assintonia das funçóes psíquicas, disto decorrendo fragmentação da personalidade e perda de contato com a realidade.

O perigo mais aparente é o de acreditar tanto nos simulacros que se acaba por tomá-los como reais. Formas diversas de esquizofrenia ou de solipsismo ${ }^{10}$ poderiam sancionar gosto demasiado pelas criaturas virtuais com as quais cada vez mais devem conviver. A fuga do verdadeiro real e o refúgio num real de síntese vão, sem dúvida, permitir às novas sociedades invadidas por desemprego estrutural fornecer, a milhóes de ociosos 
forçados, alucinações virtuais, drogas visuais, capazes de ocupar corpos e espíritos, mentes e corações ao mesmo tempo em que se desenvolverão novos mercados e, também, novas formas de controle social.

Todas estas condições sociais que fundamentam os prejuízos da "formação", cada vez mais desumana, vêm constituir a essência do conceito de "indústria cultural" que atualmente se reafirma na consolidação da chamada "realidade virtual". É o "virtual" que se torna "real" substituindo a "realidade" que se "converte" em "virtual", desertando idéias, sentimentos e valores dos sujeitos em suas relações com o mundo objetivo - seus familiares, amigos, colegas de trabalho, vizinhos, conhecidos, companheiros de ideais, companheiros de lazer -, desagregando seu "eu" interior.

Constatar e pensar a conjuntura atual como deserto e desertificação é também pensar a produção de um tipo de "sujeito humano" que somente monologa num universo mudo e destituído de sentido, vivendo um "solilóquio" que passa a se desenvolver, a partir da infância, atingindo a idade adulta e aí permanecendo de forma brutal, isolando as mentes e os corações nos seus "mundos" vividos, que cada vez se tornam mais "carentes", e, conseqüentemente, cada vez mais insatisfeitos, com um maior número de necessidades ${ }^{11}$ "produzidas".

É a insatisfação "produzida" socialmente e manifestada de forma violenta contra as pessoas, a natureza, as coisas, o mundo, contra tudo e todos que não podem ser manipulados ou apropriados. Agnes Heller e Ferenc Fehér, analisando a condição "pós-moderna”, cunharam o mundo hodierno com a expressão "sociedade insatisfeita", uma sociedade em que as ordens sociais e as pessoas se tornam contingentes. Numa "sociedade insatisfeita", afirmam,

(...) todas as ordens sociais e políticas podem com igual facilidade existir como não existir, podem ser de uma forma ou de outra. Do mesmo modo, a pessoa individual pode existir como também não existir nela, e nela desempenhar tanto um papel quanto outro. Contudo, embora todas as ordens sociais possam ser diferentes do que são, as ordens sociais decisivas podem permanecer inalteradas (embora não por alguma necessidade) durante os anos de formação do indivíduo ou pelo menos sofrer apenas lentas mudanças. Embora todas as pessoas sejam portadoras dessas possibilidades ilimitadas, tendo escolhido um caminho na vida, a pessoa individual começa a ver-se diante de possibilidades reduzidas e oportunidades sempre menores de novo começo. Além disso, o contexto pode 
Repensando e ressignificando a gestão democrática da educação...

virar um estorvo para as pessoas que escolhem um caminho de sua preferência, e algumas possibilidades jamais ocorrerem para aquelas que escolheram um determinado caminho na vida. Como disse o filósofo alemão Koselleck, há um enorme abismo entre esperanças e experiência. As esperanças estão impregnadas de contingência, mas o que experimentamos são os difíceis fatos da vida, a limitação factual de nossas possibilidades. A discrepância entre esperança e experiência é motivo de constante insatisfação e descontentamento. (Heller \& Fehér, 1998, p. 35-36)

Esta "sociedade insatisfeita", repleta de ressentimentos, é denominada de "sociedade transbordante", por Henri-Pierre Jeudy (1995). Todavia não se trata de uma sociedade transbordante de sentido porque dá em espetáculo a realidade, mas porque se situa além da espectalurização, neutralizando a oposição entre a realidade e os seus simulacros mediáticos, banalizando tudo e todos. Compreende-se, então, que a crítica da sociedade do espetáculo, a partir da defasagem com relação a uma suposta realidade exterior que lhe servisse de referente, tornou-se obsoleta, visto ter se integrado ao próprio sistema mediático, servindo de alimento ao próprio funcionamento das redes de informação.

A natureza dissuasiva desta realidade e o devir virulento do sentido coincidem com o espectro das angústias e dos medos difusos de catástrofes. É esse o espectro que as "sociedades" atuais procuram de todas as formas exorcizar por meio do recente retorno aos valores morais e da implantação dos dispositivos de segurança. Esse retorno, dos valores morais, apresenta-se, assim, como uma espécie de tábua de salvação destinada a criar a imagem da segurança perante a ocorrência dos perigos que espreitam os seres humanos, perigos que a fluidez das imagens e a dos discursos não cessam de ingurgitar o nosso cotidiano.

Diante dos elementos examinados acima, característicos da "sociedade insatisfeita" e "transbordante", urge repensar como humanizar a formação dos seres humanos que habitam o nosso planeta! Que decisões, quanto a finalidades e conteúdos, devem ser tomadas para a humanização da formação que a escola e a família, enfim, todos os aparelhos hegemônicos do Estado, necessitam propiciar como máxima prioridade? Que "conteúdos da aprendizagem, a serem ensinados como conteúdos de vida e que devem abranger os conceitos científicos da cultura erudita e os conteúdos éticos de convivência social" (Ferreira, 2003a, p. 113), devem ser priorizados e trabalhados? Eis o compromisso do coletivo dos profissionais da educação, dos políticos e dirigentes do país e da 
hegemonia mundial: a humanização da formação para a cidadania por meio de conteúdos que possam desenvolver "seres humanos fortes intelectualmente, ajustados emocionalmente, capazes tecnicamente e ricos de caráter" (idem, ibid.).

Cidadania como conceito que melhor expressa a reabsorção dos bens sociais pelo conjunto dos cidadãos e entendida como "capacidade conquistada por alguns indivíduos, ou (no caso de uma democracia efetiva) por todos os indivíduos, de se apropriarem dos bens socialmente criados, de atualizarem todas as potencialidades de realização humana abertas pela vida social em cada contexto historicamente determinado" (Coutinho, 2000, p. 50).

A cidadania, no entanto, compreendida como soberania, implica autoconsciência. Sob as condições constituídas, com a formação da sociedade global, as possibilidades da autoconsciência, por mais que se tenham "ampliado" estes horizontes de possibilidades, ainda são limitadas. Poucos são os que dispõem de condições para se informarem, para compreenderem o "bombardeio" de informaçóes que recebem na "avalanche" de velocidade violenta com que ocorrem. Poucos são os que têm condições de se posicionarem diante dos acontecimentos mundiais, tendo em conta suas implicações locais, regionais, nacionais, continentais. Somente quando se criam as condições mais plenas para a elaboração da autoconsciência, no sentido de consciência para si, então a cidadania realiza-se propriamente como soberania. Isso significa criar condições plenas para todos os seres humanos no planeta, num processo de autoconsciência que só se dará pelo conhecimento, pelas condições dignas de vida e pela participação na vida societária mundial, o que vai exigir uma outra qualidade e quantidade de conhecimento a ser adquirido.

Se está em curso a formação de um "novo cidadão do mundo", faz-se necessário entender esta contradição, pois a formação para a cidadania necessita apoiar-se na formação desse novo cidadão sem se descuidar da "cidadania" que lhe pertence como direito, pelo nascimento, em seu país. O estatuto e o valor da formação para a cidadania, hoje, necessitam se constituir de todos os elementos e recursos que permitam ao novo cidadão ter possibilidade de trânsito entre as culturas dos diferentes povos. E transitar com uma compreensão democrática de respeito a todas as diferenças e com a permanente possibilidade de acesso aos recursos necessários a essa formação, e que esta se assente em uma 
Repensando e ressignificando a gestão democrática da educação...

nova "ética humana" alicerçada na solidariedade e na justiça social, no respeito às diferenças e aos direitos de todos.

Tais compreensões e conteúdos são prioritários na formação para a cidadania, responsabilidade do profissional da educação para o qual devem ser fornecidas a formação e as condições dignas para que este compromisso profissional se efetive. Isso implica sólida formação e salários dignos que lhe permitam não só adquirir os bens culturais necessários à sua profissão como as condições de contínua qualificação. No entanto, percebese, no conjunto das reformas, o descomprometimento com a formação inicial, a supervalorização de uma política de formação em serviço que ocorre, de um modo geral, de forma aligeirada e a inexistência de políticas de valorização desses profissionais. Na verdade, a política de formação continuada de professores tem se tornado uma política de descontinuidade, pois "caracteriza-se pelo eterno recomeçar em que a história é negada, os saberes são desqualificados, o sujeito é assujeitado, porque se concebe a vida como um 'tempo zero'. O trabalho não ensina, o sujeito não flui, porque antropomorfiza-se o conhecimento e objetiva-se o sujeito" (Collares et al., 1999, p. 212). Neste sentido é possível questionar sobre o papel e as finalidades da formação dos profissionais da educação, por parte do Estado brasileiro, quando no contexto da reforma educacional se desrespeita essa formação pela desprofissionalização docente.

$\mathrm{O}$ que se verifica atualmente é que, tanto as pessoas que vivem, padecem ou desfrutam das mais diversas situaçôes, como as que se empenham em compreender e explicar o que vai pelo mundo, todos estão empenhados em refletir sobre a formação, a conformação e a transformação dos indivíduos na contemporaneidade. Mesmo sem se ter "tornado" cidadão, pela ausência dos elementos constitutivos desta condição, hoje o ser humano está "atento" e "perdido", à deriva do que fazer e de como se realizar.

\section{Gestão da educação na "cultura globalizada”: ressignificar é preciso!}

A compreensão do significado da gestão da educação, nos tempos hodiernos, necessita, a partir do seu sentido etimológico, ser vinculada às exigências do mundo globalizado com toda a sua complexa rede de determinações, tendo como referência fundamental a formação para a cidadania na "cultura globalizada". 
Gestão significa tomada de decisões, organização, direção. Relaciona-se com a atividade de impulsionar uma organização a atingir seus objetivos, cumprir suas responsabilidades. Gestão da educação significa ser responsável por garantir a qualidade de uma "mediação no seio da prática social global” (Saviani, 1980, p. 120), que se constitui no único mecanismo de hominização do ser humano, que é a educação, a formação humana de cidadãos. Seus princípios são os princípios da educação que a gestão assegura serem cumpridos - uma educação comprometida com a "sabedoria" de viver junto respeitando as diferenças, comprometida com a construção de um mundo mais humano e justo para todos os que nele habitam, independentemente de raça, cor, credo ou opção de vida (Ferreira, 2004, p. 306-307).

Significa tomar decisões, organizar e dirigir as políticas educacionais que se desenvolvem na escola comprometidas com a formação da cidadania, no contexto da complexa "cultura globalizada". Isso significa aprender com cada "mundo" diferenciado que se coloca, suas razões e lógica, seus costumes e valores que devem ser respeitados, por se constituírem valores, suas contribuições que são produção humana. Estas compreensões têm como objetivo, se possível, "iluminar" um campo profissional "minado" de todas essas incertezas e inseguranças, tornando-o conseqüente com o próprio conceito e nome, a fim de tomar decisôes sobre como formar e como garantir a qualidade da educação a partir de princípios e finalidades definidos coletivamente, comprometidos com o bem comum de toda a humanidade.

Não é tarefa fácil, mas necessária! É um compromisso de quem toma decisões - a gestão -, de quem tem consciência do coletivo - democrática -, de quem tem a responsabilidade de formar seres humanos por meio da educação. Assim se configura a gestão democrática da educação que necessita ser pensada e ressignificada na "cultura globalizada", imprimindo-lhe um outro sentido.

A "cultura globalizada" 12 significa uma poderosa imagem cultural que exige um novo nível de conceptualização de todas as inúmeras e incontáveis culturas locais, regionais, estatais, ocidentais e orientais, do Norte e do Sul que estão "postas a nu", divulgadas ao mundo que assiste encantado e perplexo a este "multiculturalismo", o qual necessita ser acatado e respeitado. "Cultura globalizada" é a expressão que contém a diversidade de tudo e de todos na unidade dos limites do mundo. Con- 
Repensando e ressignificando a gestão democrática da educação...

traditório "conceito" que necessita ser investigado e compreendido para se poder empreender a gestão democrática da educação.

O novo sentido da gestão democrática da educação é o de humanizar a formação nesta "cultura globalizada" dirigida, virtualmente, pelo capitalismo. Este novo sentido exige que os educadores - professores, pais, gestores, políticos e todos que tomam decisóes sobre os destinos da humanidade - comecem a inquietar-se com as conseqüências psicológicas e sociais que os excessivos uso e consumo de universos virtuais criam. Uma "realidade irreal" que passa a constituir-se em um "virtual real".

À compreensão de gestão como tomada de decisôes vale acrescer a contribuição de Cury (2002), quando salienta que este termo também provém do verbo latino gero, gessi, gestum, gerere, que significa: levar sobre si, chamar a si, exercer, gerar. Assim como em um dos substantivos derivados deste verbo, gestatio, ou seja, gestação, percebe-se o ato pelo qual se traz em si e dentro de si algo novo, diferente: um novo ente. "Da mesma raiz provêm os termos genitora, genitor, germen. A gestão, neste sentido, é, por analogia, uma geração similar àquela pela qual a mulher se faz mãe ao dar a luz a uma pessoa humana” (Cury, 2002, p. 164).

Pode-se vislumbrar aqui a postura metodológica da maiêutica socrática. A gestão implica um ou mais interlocutores com os quais se dialoga pela arte de interrogar e pela paciência em buscar respostas que possam auxiliar no governo da educação segundo a justiça. Nessa perspectiva, a gestão implica o diálogo como forma superior de encontro das pessoas e solução de conflitos. (Cury, 2002, p. 165)

Respeito, paciência e diálogo como encontro de idéias e de vidas "única forma superior de encontro" dos seres humanos, os únicos seres vivos que possuem esta condição e possibilidade e que não a utilizam. Diálogo, como o fundamental caminho em todas as suas possíveis formas, entendido como "o reconhecimento da infinita diversidade do real que se desdobra numa disposição generosa de cada pessoa para tentar incorporar ao movimento do pensamento algo da inesgotável experiência da consciência dos outros" (Ferreira, 2000, p. 172). Diálogo como uma generosa disposição de abrir-se ao "outro" que irá "somar" compreensões convergentes ou divergentes no sentido da construção da humanização das relações. Diálogo como confraternização de idéias e de culturas que se respeitam porque constituem diferentes produçôes hu- 
manas. Diálogo como a verdadeira forma de comunicação humana, na tentativa de superar as estruturas de poder autoritário que permeiam as relaçôes sociais e as práticas educativas a fim de se construir, coletivamente na escola, na sociedade e em todos os espaços do mundo, uma nova ética humana e solidária. Uma nova ética que seja o princípio e o fim da gestão democrática da educação comprometida com a verdadeira formação da cidadania.

Fraternidade, solidariedade, justiça social, respeito, bondade e emancipação humana, mais do que nunca, precisam ser assimilados e incorporados como consciência e compromisso da gestão democrática da educação - princípios que necessitam nortear as decisões a serem tomadas no sentido da humanização e da formação de todas as pessoas que vivem neste planeta.

\section{Recebido e aprovado em outubro de 2004.}

\section{Notas}

1. Para Norbert Elias são três as condições que teriam definido o curso do processo civilizatório: a primeira é a centralização do poder por meio da constituição do Estado moderno; da emergência portanto de um espaço, configurado como ordem legal e, até certo ponto, legítima, e onde a garantia da ordem deriva de um monopólio. A segunda condição que define o curso do processo civilizatório é a codificação dos comportamentos, sua normatização. É preciso que as pessoas civilizadas compartilhem regras comuns a respeito de como se comportar em sociedade. Elias mostra a lenta emergência desse processo de codificação que marca o advento da Era Moderna e que se constrói originalmente sob a forma de um processo de educação das elites. A última condição é a do interesse estratégico que podem ter - ou não - indivíduos confrontados com o monopólio da força exercido pelo Estado e conscientes das regras de comportamento do mundo civilizado, em abrir mão da força nas suas relações recíprocas, em favor de procedimentos definidos pela capacidade de influência e de persuasão. A incidência dessas três condições históricas, e portanto do processo civilizatório, sobre a agressividade individual é analisada por Elias, mostrando que a civilização supõe a passagem de uma situação globalmente definida em termos de heteroviolência a uma situação definida em termos de autoviolência. Para que o indivíduo prefira a influência e a persuasão ao uso da força, é preciso que ele exerça sobre si mesmo um autocontrole, que ele seja capaz de controlar sua própria agressividade. Neste sentido a generalização de situações em que o uso da força passa a ser preferido, em detrimento das categorias de relacionamento próprias do mundo civilizado, estaria a indicar uma reversão do processo civilizatório (Elias, 1973; 1975).

2. Na linguagem do espetáculo, isso significa que a difusão das informações é simultânea à sua produção, isto é, "ao vivo".

3. A expressão "cultura globalizada", aqui utilizada, significa o rico, complexo e imenso conjunto de culturas que se entrecruzam no planeta impondo suas peculiaridades e diferen- 
ças e exigindo respeito aos seus modus vivendi, formatos e desenvolvimentos. São inúmeras e incontáveis culturas que, concomitantemente, desenvolvem-se, expõem-se e defendem seus princípios, valores e costumes intercambiando diferenças e antagonismos (Ferreira, 2003b, p. 31).

4. Tecnologias da Informação e Comunicação

5. Para Henry-Pierre Jeudi, a realidade banalizada tornou-se insignificante. As sociedades atuais são transbordantes. Mas que terão elas hoje em excesso que as faça transbordar? Pessoas? Objetos? Acontecimentos? Se o autor entendesse que o mundo atual tem objetos em excesso, incorreria nas críticas dos que fazem notar que cerca de dois terços da humanidade vivem ainda hoje na penúria, na carência dos mais elementares meios de subsistência. Se entendesse que há hoje um excesso de pessoas, atrairia as críticas dos que assinalam a baixa da natalidade dos países industrializados e o conseqüente processo de envelhecimento da população, que ocorre nesses países. Se entendesse que é de um excesso dos acontecimentos que transborda a sociedade atual, seria criticado pelos que vêem o mundo contemporâneo como um processo de rarefação e de consumação da História. Portanto não são objetos, pessoas ou acontecimentos que estão hoje em excesso nas sociedades - é de sentido que as sociedades transbordam. Para este sociólogo francês, é a avalanche dos discursos e das imagens que circulam no espaço mediático que torna as coisas, os objetos, os acontecimentos e as pessoas insignificantes e é precisamente sobre essa insignificância da realidade, sobre este processo de banalização, que se funda o excesso ou a mais-valia dos discursos e das imagens que circulam no espaço público. A própria realidade é assim substituída e dissuadida pela proliferação do sentido, acedendo desse modo a um estatuto de pretexto de uma nova realidade, de uma realidade de natureza discursiva e imagética (Jeudi, 1995).

6. Banalização significa supressão de marcas distintivas; ação de tornar banal, tornar comum, de entrar nos hábitos (Oliveira, 2000, p. 48), tornar vulgar (Ferreira, 2001, p. 262). É uma categoria que ascende vertiginosamente com o processo de agudização do capitalismo globalizado sob a égide do Estado mínimo e do desenvolvimento da tecnologia e dos meios de comunicação.

7. De acordo com Sousa Santos, 54 dos 84 países menos desenvolvidos viram seu PNB per capita decrescer nos anos de 1980; em 14 deles a diminuição rondou os 35\%. Segundo o Relatório do Programa para o Desenvolvimento das Nações Unidas de 2001 (PNUD, 2001), mais de 1,2 bilhão de pessoas (pouco menos de $1 / 4$ da população mundial) vivem em pobreza absoluta, ou seja, com um rendimento inferior a um dólar por dia e outros 2,8 bilhōes vivem apenas com o dobro desse rendimento (PNUD, 2001, p. 9). Segundo esse mesmo relatório, $46 \%$ da população mundial que vive em pobreza absoluta está na África subsaariana, $40 \%$ no sul da Ásia e $15 \%$ no Estremo Oriente, no Pacífico e na América Latina. Conforme o Relatório do Desenvolvimento do Banco mundial, de 1995, o conjunto dos países pobres, onde vive $85,2 \%$ da população mundial, detém apenas $21,5 \%$ do rendimento mundial, ao passo que o conjunto dos países ricos, com $14,8 \%$ da população mundial, detém $78,5 \%$ do rendimento mundial.

8. Antônimo de ânimo (do latim animus), que significa coragem, força, vida; a depressão é desânimo e significa enfraquecimento, debilidade, morte na vida.

9. Saviani ensina "que só se aprende, de fato, quando se adquire um habitus, isto é, uma disposição permanente, ou, dito de outra forma, quando o objeto de aprendizagem se converte numa espécie de segunda natureza" (Saviani, 2003, p. 20). Para aprofundamento do conceito, consultar o texto "Sobre a natureza e especificidade da educação", em Saviani, 2003. 
10. Solipsismo é a doutrina segundo a qual a única realidade no mundo é o "eu". Atitude que consiste em sustentar que o " $\mathrm{eu}$ " individual de que se tem consciência, com suas modificações subjetivas, é que forma toda a realidade. Pode ser também interpretado como "vida ou costume de quem vive na solidão" (Ferreira, 1999, p. 1.879).

11. As necessidades podem ser descritas como sentimentos conscientes de que "falta alguma coisa", é "uma falta de...". Em conseqüência o termo "necessidade" não indica um determinado sentimento concreto, mas muitos sentimentos distintos na condição de assinalar uma falta. Nem todos os sentimentos, porém, podem assinalar uma "falta", mas muitos, e tão diferentes quanto a fome, a curiosidade, a ansiedade, o amor e inúmeros outros, certamente o fazem.

12. Esta expressão é, aqui, utilizada com a intencionalidade de chamar a atenção para a complexa "teia de relações" que se estabeleceu e se estabelece, a todo momento, numa rede de informações e inter-relações que "bombardeiam" mentes e corações com novos/velhos valores, idéias, costumes, descobertas, invençōes, nomenclaturas diferenciadas, contraditórias e díspares, povoando conjuntamente todos os espaços. Essa intencionalidade se insere no que Ianni revela: "Quando muitos imaginavam que a máquina do mundo já havia realizado suas principais potencialidades, ela surpreende praticamente a todos e faz ruir esquemas, estratégias, interpretações, arranjos políticos, alianças econômicas e geopolíticas, conveniências e cumplicidades" (1995, p. 22), recobrindo o mundo de novos significados que passam a compor uma nova "cultura", agora entendida como uma "cultura global" que induz, suscita, fascina, amedronta, encanta, aterroriza e obriga a "criar", por meio da interpretação e do sonho, novas realidades culturais, novas formas de viver, de produzir a existência, novas formas de gestão comprometidas com o bem comum de toda a humanidade (Ferreira, 2003a).

\section{Referências bibliográficas}

ADORNO, T. W. "Educação após Auschwitz". Trad. de Aldo Onesti. In: Conn, G. Adorno, Theodor W. Coleção Grandes Cientistas Socais. São Paulo: Ática, 1986.

ARENDT, H. La crise de la culture. Paris: Galimard, 1994.

BÁRCENA, F.; MÈLICH, J.C. La educación como acontecimiento ético: natalidad, narración y hospitalidad. Barcelona: Paidós, 2000.

BOURDIEU, P. Razões práticas: sobre a teoria da acção. Oeiras: Celta Editora, 1997.

CARNOY, M.; CASTELLS, M. The new global economy in the information age. University Park, PA: Pennsylvania State University Press, 1993.

CARNOY, M. Mundialização e reforma na educação: o que os planejadores devem saber. Brasilia: UNESCO, 2002. 
Repensando e ressignificando a gestão democrática da educação...

CASTELLS, M. The rise of the network society. Londres: Blackwell, 1996.

COLLARES, C.A.; MOYSÉS, M.A.A.; GERALDI, J.W. Educação continuada: a política da descontinuidade. Educação \& Sociedade, Campinas, a no XX, n. 68, dez. 1999. p. 202-219.

COUTINHO, C.N. Contra a corrente: ensaios sobre a democracia e o socialismo. São Paulo: Cortez, 2000.

CURY, C.R.J. Gestão democrática da educação: exigências e desafios. Revista Brasileira de Política e Administração da Educação, São Bernardo do Campo, v. 18, n. 2, jul./dez. 2002a.

CURY, C.R.J. Direito à educação: direito à igualdade, direito à diferença. Cadernos de Pesquisa, Fundação Carlos Chagas, Campinas: Autores Associados, n. 116, jul. 2002.

DRAIBE, S. As políticas sociais e o neoliberalismo. Revista da USP, São Paulo, n. 17, 1993.

ELIAS, N. La civilización des moeurs. Paris: Calmann-Lévy, 1973.

ELIAS, N. O processo civilizador. V. I. Rio de Janeiro: Zahar, 1994.

FERREIRA, A.B.H. Novo Aurélio - Dicionário da Língua Portuguesa. 3. ed. Rio de Janeiro: Nova Fronteira, 1999.

FERREIRA, N.S.C. Tecnologia educacional e o profissional no Brasil: sua formação e a possibilidade de construção de uma cultura humana. Revista Tecnologia Educacional, ano XXVI, v. 26, n. 141, abr./mai./jun. 1998.

FERREIRA, N.S.C. Education technology and the professional in Brazil: his formation and the possibility of human culture. Bulletin of Science, Technology \& Society. Thousand Oaks/London/New Delhi, Sage Science Press, v. 19, n. 3, June 1999. p. 206-209.

FERREIRA, N.S.C. Gestão democrática da educação para uma formação humana: conceitos e possibilidades. Em Aberto. Gestão escolar e formação de gestores. Instituto Nacional de Estudos e Pesquisas Educacionais, Brasília, v. 17, n. 72, jun. 2000. 
FERREIRA, N.S.C. Tecnologia educacional e gestão da educação: entre a utopia e a realidade. In: Tecnologias em educação: estudos e investigações. Anais do XI Colóquio da AFIRSE, Lisboa: Universidade de Lisboa, 2001.

FERREIRA, N.S.C. Violência e paz: a exigência de novas políticas e ações integradas. In: Violência e indisciplina na escola. Anais do XI Colóquio da AFIRSE, Lisboa: Universidade de Lisboa, 2002a.

FERREIRA, N.S.C. Formação continuada e gestão da educação no contexto da "cultura globalizada". In: Ferreira, N.S.C. Formação continuada e gestão da educação. São Paulo: Cortez, 2003a.

FERREIRA, N.S.C. Poderemos trabalhar juntos na sociedade mundializada? Desafios para os educadores. In: PorTo, T.E. Redes em construção: meios de comunicação e práticas educativas. Araraquara/ SP: JM, 2003b.

FERREIRA, N.S.C. Gestão democrática da educação: ressignificando conceitos e possibilidades. In: Ferreira, N.S.C.; Aguiar, M.A. Gestão da educação: impasses, perspectivas e compromissos. 4. ed. São Paulo: Cortez, 2004.

FRIGOTTO, G. Educação e crise: perspectivas de final de século. Petrópolis: Vozes, 1998.

GIDDENS, A. Sociology. Oxford: Polity Press, 1990.

GIDDENS, A. As conseqüências da modernidade. Oeiras: Celta Editora, 1998.

GIDDENS, A. O mundo na era da globalização. Lisboa: Editorial Presença, 2000.

HELLER, A. Historia y futuro. ¿Sobreviverá la modernidad? Barcelona: Ediciones Península, 2000.

HELLER, A. Além da justiça. Rio de Janeiro: Civilização Brasileira, 1998.

HELLER, A.; FEHÉR, F. A condição politica pós-moderna. Rio de Janeiro: Civilização Brasileira, 1998. 
Repensando e ressignificando a gestão democrática da educação...

HIRSCH, J. Globalización, capital y Estado. México: Universidad Autónoma Metropolitana, 1998.

IANNI, O. Teorias da globalização. Rio de Janeiro: Civilização Brasileira, 1995.

IANNI, O. O cidadão do mundo. In: Lombardi, J.; Saviani, D.; SAnfelice, J. Capitalismo, trabalho e educação. Campinas: Autores Associados/HISTEDBR, 2002.

JEUDY, H.P. A sociedade transbordante. Lisboa: Edições Século XXI, 1995.

OLIVEIRA, A.D.B. Dicionário de Metalinguagens da Didática. Porto: Porto Editora, 2000.

PARO, V.H. Administração escolar: introdução crítica. 9. ed. São Paulo: Cortez, 2000.

PAULINO, A.R. Criminalidade global e insegurança local - o caso de Moçambique. In: Colóquio Direito e Justiça no Século XXI. Coimbra: Universidade de Coimbra, 29-30 mai. 2003. (mimeo)

SANTOS, M. Por uma outra globalização: do pensamento único à consciência universal. 6. ed. Rio de Janeiro/São Paulo: Record. 2001.

SAVIANI, D. Educação: do senso comum à consciência filosófica. São Paulo: Cortez, 1980.

SAVIANI, D. Sobre a natureza e especificidade da educação. In: SAVIANI, D. Pedagogia histórico-crítica: primeiras aproximações. 8. ed. revista e ampliada. Campinas/SP: Autores Associados, 2003.

SOUSA SANTOS, B.S. A transição paradigmática: da regulação à emancipação. Oficina do CES. Coimbra: Universidade de Coimbra, 1991.

SOUSA SANTOS, B.S. Os processos de globalização. In: Sousa SANTOS, B.S. Globalização: fatalidade ou utopia. Porto: Afrontamento, 2001.

SOUSA SANTOS, B.S. O fim das descobertas imperiais. In: OLIVEIRA, I.B.; SGARBI, P. Redes culturais: diversidade e educação. Rio de Janeiro: DP\&A, 2002. 
TOLDA, J. Globalização e espaços locais: economia do conhecimento e da inovação. In: ReIs, J.; BAgANHA, M.I. A economia em curso: contextos e mobilidades. Porto: Afrontamento, 2001. p. 87-110.

WATERS, M. Globalization. London: Routledge, 1995.

ZUIN, A.A.S. Indústria cultural globalizada e os prejuízos da formação. In: PuCCI, B. Teoria crítica, ética e educação. Piracicaba/Campinas: Editora da UNIMEP/Autores Associados, 2001. 